\title{
GERMINAÇÃO DE SEMENTES DE ARATICUM: DOSES DE GA 3 E PERÍODOS DE EMBEBIÇÃO
}

Jéssica Aparecida Freitas, Willian Rodrigues Macedo

Universidade Federal de Viçosa - UFV. E-mail: wrmacedo@ufv.br

\section{RESUMO}

Sementes de Annona crassiflora apresentam dormência morfofisiológica, e estudos de mecanismos que permitam a sua germinação, garantirão a sobrevivência da espécie. Objetivou-se verificar ação do ácido giberélico $\left(\mathrm{GA}_{3}\right)$ em distintos períodos de imersão na superação de dormência das sementes. 0 experimento foi conduzido em delineamento inteiramente casualizado (DIC), com 630 sementes divididas em 7 tratamentos (seccionamento mecânico+ $1000 \mathrm{mg} \mathrm{L}^{-1}$ de $\mathrm{GA}_{3}$ nos períodos de 24, 48 e 72 horas; seccionamento mecânico $+2000 \mathrm{mg} \mathrm{L}^{-1}+\mathrm{GA}_{3}$ nos períodos de 24,48 e 72 ; e controle). 0 tratamento onde houve o seccionamento mecânico $+2000 \mathrm{mg} \mathrm{L}^{-1}$ de $\mathrm{GA}_{3}$ por 72 horas aumentou a germinação das sementes em $10 \%$ quando comparado ao controle (semente somente seccionada).

Palavras-chave: cerrado; Annonaceae; seccionamento; reguladores vegetais.

\section{ARATICUM SEEDS GERMINATION: GA 3 LEVELS AND SOAKING TIME}

\begin{abstract}
The Annona crassiflora seeds showed morphophysiological dormancy and studies of breaking dormancy were necessary to the survival of the species. We evaluate de gibberellic acid $\left(\mathrm{GA}_{3}\right)$ effect under different soaking times on dormancy breaking. The experimental design was completely randomized, with 630 seeds distributed in 7 treatments (mechanical scarification $+1000 \mathrm{mg} \mathrm{L}^{-1}$ de $\mathrm{GA}_{3}$ in periods of 24,48 e 72 hours; (mechanical scarification $+2000 \mathrm{mg} \mathrm{L}^{-1}$ de $\mathrm{GA}_{3}$ in periods of 24,48 e 72 hours; plus control treatment). The treatment with mechanical scarification $+2000 \mathrm{mg} \mathrm{L}^{-1}$ de $\mathrm{GA}_{3}$ for 72 hours improve de seed germination in $10 \%$, when compared to control.
\end{abstract}

Key words: cerrado; Annonaceae; seed section; plant growth regulators.

\section{INTRODUÇÃO}

O Cerrado é o segundo maior domínio da América do Sul, apresentando a maior diversidade vegetal dentre as savanas do mundo, incluindo alto grau de endemismo, considerado um hotspot mundial de biodiversidade, mas encontra-se em risco devido à pressão da atividade antrópica (KLINK; MACHADO, 2005), o que dificulta a obtenção de informações sobre as espécies nativas, bem como a avaliação do potencial uso comercial dessas. O araticum (Annona crassiflora) pertence à família Annonaceae, seu fruto possui sabor e odor muito característicos (SILVA et al., 2007) além de propriedades nutricionais e organolépticas muito valorosas (TELLES et al., 2003).

A germinação de suas sementes se dá após um longo período de dormência morfofisiológica, ocorrendo após 230 dias da maturação da semente (RIZZINI, 1973; SILVA et al., 2007), sendo possível recorrer às técnicas já estabelecidas para cultivos comerciais para a superação dessa dormência, como é o caso da utilização de giberelina (RIBEIRO et al., 2000), hormônio este responsável pela ativação de enzimas hidrolíticas (TAIZ; ZEIGER, 2013). O interesse pela produção de mudas de araticum se dá pela crescente demanda por mudas nativas utilizadas na recuperação de áreas degradadas ou para recomposição de reserva legal nas propriedades rurais (JUNQUEIRA et al., 2008). Sendo assim, objetivamos verificar a eficiência de diferentes doses de ácido giberélico e os períodos distintos de imersão sobre a germinação das sementes de araticum (Annona crassiflora), no intuito de viabilizar a produção de mudas em viveiro comercial. 


\section{MATERIAL E MÉTODOS}

O trabalho foi desenvolvido no laboratório de Fisiologia do Metabolismo e Produção Vegetal (LAFIMEPRO), da Universidade Federal de Viçosa - Campus Rio Paranaíba e no viveiro de mudas da empresa Agro-Ambient (Rio Paranaíba-MG). Inicialmente frutos maduros, considerados àqueles que se encontravam no solo sob a planta mãe (GOLIN et al., 2011), foram coletados de plantas nativas entre os meses de março a abril de 2015, em três áreas do Cerrado Mineiro, nos munícipios de São Gotardo e Matutina, ambos na região do Alto Paranaíba, MG. Posteriormente, esses frutos foram despolpados e lavados em água corrente sobre uma peneira, até a total retirada da mucilagem, em seguida as sementes foram secas à sombra por 2 horas, metodologia adaptada de Bernardes et al. (2007). Para as análises em laboratório as sementes foram desinfetadas, de acordo com metodologia adaptada de Silva et al. (2017), onde sementes foram imersas em solução de hipoclorito de sódio $2,5 \%$ de cloro ativo, na proporção de $10 \mathrm{~mL}$ para cada $1000 \mathrm{~mL}$ de água por 10 minutos, e em seguida, enxaguadas em água corrente para a total retirada de resíduo de hipoclorito de sódio dos tegumentos.

Inicialmente se conduziu um ensaio para averiguar a viabilidade das sementes utilizadas neste experimento, mediante teste de tetrazólio, aplicando o procedimento adaptado de Gimenez et al. (2014), onde 40 sementes foram subdivididas em 4 tratamentos, com 10 sementes cada, metade das amostras foram submetidas a seccionamento mecânico, com o auxílio de uma tesoura de poda, fazendo-se um corte no tegumento em região oposta a micrópila, enquanto o outro grupo permaneceu com o tegumento intacto, todas as sementes foram imersas em solução de tetrazólio $(0,1 \%)$, em dois distintos períodos de imersão 2 ou 4 horas.

Posteriormente outro ensaio foi realizado para avaliar o efeito de doses do ácido giberélico e períodos de embebição deste biorregulador, constituindo sete tratamentos: tratamento 1 - Controle (somente semente seccionada); tratamento 2 - semente seccionada $+1000 \mathrm{mg} \mathrm{L}^{-1}$ de $\mathrm{GA}_{3}$ imerso por 24 horas; tratamento 3 - semente seccionada $+1000 \mathrm{mg} \mathrm{L}^{-1}$ de $\mathrm{GA}_{3}$ imerso por 48 horas; tratamento 4 semente seccionada $+1000 \mathrm{mg} \mathrm{L}^{-1}$ de $\mathrm{GA}_{3}$ imerso por 72 horas; tratamento 5 - semente seccionada + $2000 \mathrm{mg} \mathrm{L}^{-1}$ de $\mathrm{GA}_{3}$ imerso por 24 horas; tratamento 6 - semente seccionada $+2000 \mathrm{mg} \mathrm{L}^{-1}$ de $\mathrm{GA}_{3}$ imerso por 48 horas; tratamento 7 semente seccionada $+2000 \mathrm{mg} \mathrm{L}^{-1}$ de $\mathrm{GA}_{3}$ imerso por 72 horas, com três repetições de 30 sementes cada, totalizando 630 sementes, o seccionamento da semente ocorreu com auxílio de uma tesoura de poda, cortando o tegumento em duas partes e em região oposta a micrópila, a fim de evitar danos ao embrião da semente.

As sementes foram germinadas em sacos de polietileno preenchidos com substrato na proporção de 2:1 (terra de barranco e areia grossa), posteriormente ao plantio adicionou-se uma fina camada de substrato a base de casca de pinus e fibra de coco (Bioplant ${ }^{\circ}$ ), para manutenção da umidade do substrato. As sementes foram mantidas em viveiro coberto por tela de sombrite (50\% de sombreamento). As plantas foram mantidas sob irrigação constante, via aspersão a cada dois dias, para manutenção da capacidade de campo no substrato, sendo acompanhamento durante os 140 primeiros dias após o plantio (DAP).

Periodicamente, a cada sete dias, verificaram-se os tratamentos que apresentaram emergência de plântulas. Ao final de 140 dias, retiraram-se todas as sementes para avaliar a protrusão da radícula, considerando-se como germinadas as sementes que romperam 0 tegumento e iniciaram a emissão da mesma. $E$ ao término do experimento verificamos que as sementes não germinadas se encontravam em estado inicial de decomposição e elevada proliferação de microorganismos, caracterizando a sua inviabilidade germinativa.

O delineamento experimental foi inteiramente casualizados, sendo que no teste do tetrazólio foi realizada uma análise descritiva dos resultados. Para a avaliação da germinação, os dados obtidos foram submetidos à análise de variância, e ao teste de Shapiro-Wilk para verificação da normalidade, onde se constatou a necessidade de transformação dos dados em $\sqrt{x}+0,5$ (ZIMMERMANN, 2014) e por fim, as médias foram comparadas pelo teste LSD (least square difference) de Fischer, para avaliar a diferença mínima significativa entre os tratamentos, utilizou-se o software SAS 9.1 (SAS, 2009).

\section{RESULTADOS E DISCUSSÃO}

Para o teste do tetrazólio observamos que devido ao tegumento rígido e micrópila bastante reduzida, as sementes intactas 
apresentaram um baixo potencial de absorção do sal de 2,3,5-trifeniltetrazólio, com $0 \%$ de reação, ou seja, o tegumento impediu a absorção do sal, já as sementes seccionadas apresentaram maior absorção da solução de tetrazólio, consequentemente observamos $100 \%$ de coloração avermelhada, devido a total reação do sal com os prótons $\left(\mathrm{H}^{+}\right)$liberados pela respiração do embrião, e que nos permitiu concluir que todas as sementes avaliadas estavam viáveis (Figuras e

2).

Figura 1. Teste do Tetrazólio a 0,1\% por 2 horas: A - sementes seccionadas, B - sementes intactas.

A
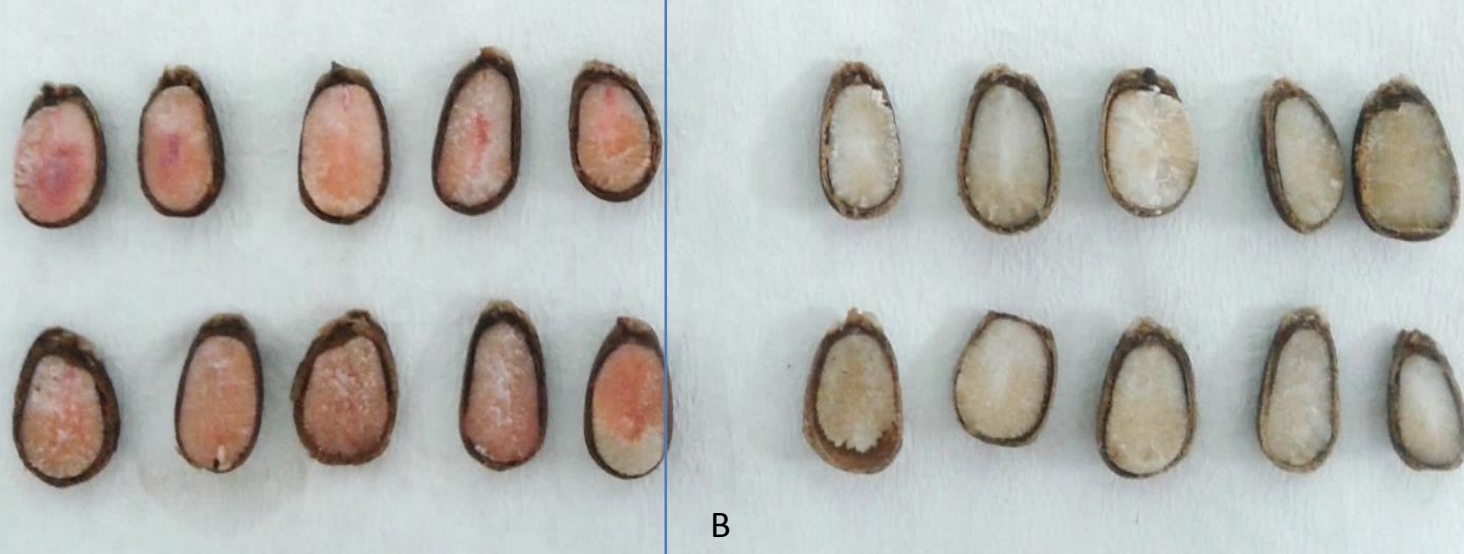

B

Figura 2. Teste do Tetrazólio a 0,1\% por 4 horas, A - sementes seccionadas, B - sementes intactas.

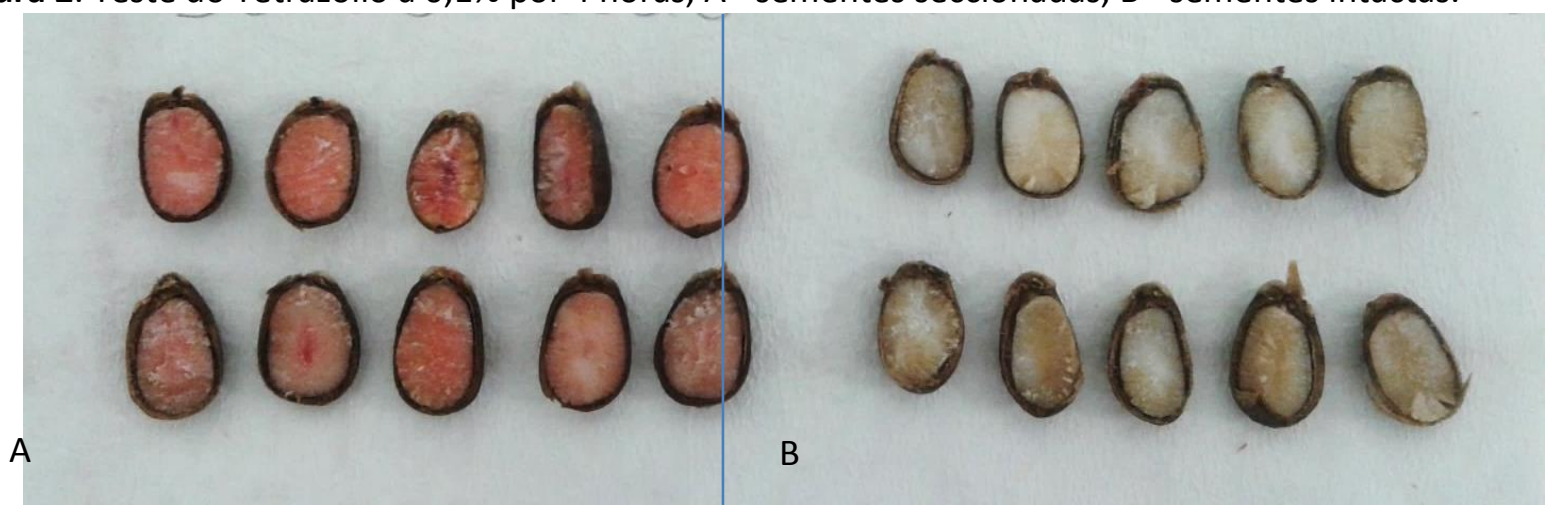

Também foi verificado que o período mais longo de imersão, 4 horas, levou a um aumento considerável da coloração das sementes seccionadas (Figura 2), se comparado ao tratamento onde a imersão ocorreu por 2 horas (Figura 1), isso pode levar a possíveis equívocos de interpretação, tendo em vista que o teste de tetrazólio utiliza da interpretação do analista para emissão do parecer final, consideramos assim que 0 teste de 2 horas permite identificação satisfatória da coloração do embrião (Figura 1).

Para o experimento com ácido giberélico, observou-se que tratamentos com a concentração de $1000 \mathrm{mg} \mathrm{L}^{-1}$ de $\mathrm{GA}_{3}$ apresentaram aumentos significativos na germinação conforme o aumento de tempo (24, 48 e 72 horas) da exposição ao ácido, quando comparado ao controle, mesmo resultado foi observado com o uso da concentração de 2000 $\mathrm{mg} \mathrm{L} \mathrm{L}^{-1}$, conforme o aumento do tempo de exposição ao $\mathrm{GA}_{3}$. Verificamos, também, que não houve nenhum indicativo de fitointoxicação do embrião quando exposto à alta concentração do regulador vegetal por um período longo de embebição (Figura 3).

Também foi verificado que as diferenças entres as germinações foram mais expressivas entre os tratamentos 1 e 7 , sendo que os tratamentos 2 e 3 não se mostraram superiores ao controle, já os tratamentos 4 e 6 demonstraram resultados muito similares entre si e não diferiram estatisticamente do tratamento 7, considerado o melhor tratamento, pois favoreceu ganhos de $10 \%$ na germinação de sementes em relação ao controle, mostrando-se o mais promissor entre todos, enquanto os 
tratamentos 4, 5 e 6 apresentaram germinação superior ao controle, respectivamente, na ordem de 5,55; 4,44 e 6,66\% (Figura 3).

Figura 3. Teste de germinação de sementes de araticum, onde: 1 (Controle); 2 (1000 $\mathrm{mg} \mathrm{L}^{-1}$ por 24 horas); 3 (1000 $\mathrm{mg} \mathrm{L}^{-1}$ por 48 horas); 4 (1000 $\mathrm{mg} \mathrm{L}^{-1}$ por 72 horas); 5 (2000 $\mathrm{mg} \mathrm{L}^{-1}$ por 24 horas); 6 (2000 $\mathrm{mg} \mathrm{L}^{-1}$ por 48 horas); 7 (2000 $\mathrm{mg} \mathrm{L}^{-1}$ por 72 horas). Comparação de médias LSD (95\% de significância), barras indicam o erro padrão da média ( \pm EPM).

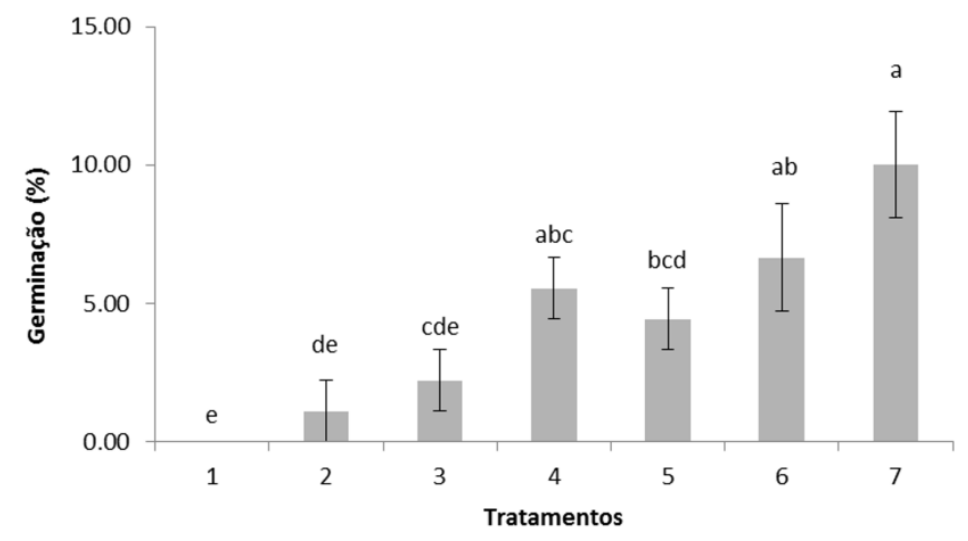

Resultados que consideremos apropriados para aplicabilidade no setor viveirista, e que corrobora com observações de Gimenez et al. (2014) que ao imergir sementes de atemóia (Annona cherimola Mill. $\times A$. squamosa $\mathrm{L}$.) em solução contendo $300 \mathrm{mg} \mathrm{L}^{-1}$ de $\mathrm{GA}_{4+7}+\mathrm{N}$-(fenilmetil) aminopurina, observaram $44 \%$ na germinação das sementes, enquanto o controle, sem o uso de regulador vegetal, apresentou apenas $5 \%$ de germinação. Essa grande variância na germinação indica que, sob condições naturais, a germinação pode se estender de dias a meses, desde que as sementes se mantenham viáveis no substrato em que se encontram, e indica também que a espécie tende a estabelecer bancos de sementes persistentes (BORGHETTI; FERREIRA, 2004). Fato característico da região do Cerrado e de ambientes que apresentam fatores ambientais estressores (seca prolongada e queimadas).

\section{CONCLUSÕES}

A avaliação da viabilidade das sementes de araticum, pelo teste de sal de tetrazólio a concentração de $0,1 \%$, é eficaz nos tempos de 2 e 4 horas, desde que as sementes sejam seccionadas para reduzir a impermeabilidade da solução do sal exercida pelo tegumento. Para estimular a germinação de sementes de araticum (Annona crassiflora) faz-se necessário realizar a seccionamento mecânico do tegumento, manter as sementes em imersão com solução do regulador vegetal $\mathrm{GA}_{3}$. A eficiência do regulador vegetal está diretamente vinculada a maior concentração e ao período mais extenso de embebição.

\section{AGRADECIMENTOS}

Ao Biólogo Willian Lopes Silva, proprietário da AgroAmbient - Assessoria AgroAmbiental e Hortaliças Orgânicas, por permitir o uso do viveiro de produção de mudas.

\section{REFERÊNCIAS}

BERNARDES, T. G.; ESTRÊLA, C., T.; NAVES, R. V.; REZENDE, C. F. A.; MESQUITA, M. A. M.; PIRES, L. L. Efeito do armazenamento e de fitohormônios na qualidade fisiológica de sementes de Araticum (Annona crassiflora Mart.). Pesquisa Agropecuária Tropical. v. 37, n. 3, p. 163-167, 2007.

BORGHETTI, F.; FERREIRA, A.G. Germinação: do básico ao aplicado. Porto Alegre: Artmed, 2004. p. 209-222.

GOLIN, V.; SANTOS-FILHO, M.; PEREIRA, M. J. B. Dispersão e predação de sementes de araticum no Cerrado de Mato Grosso, Brasil. Ciência Rural. 2011, v. 41, n.1, pp.101-107. http://dx.doi.org/10.1590/S0103$\underline{84782011000100016 .}$.

GIMENEZ, J. I.; FERREIRA, G.; CAVARIANI, C. Tetrazolium test for assessment of seed viability of atemoya (Annona cherimola Mill. X $A$. 
squamosa L.). Journal of Seed Science, v. 6, n.3, p. 357-361, 2014. http://dx.doi.org/10.1590/2317$1545 \mathrm{v} 36 \mathrm{n} 31004$.

JUNQUEIRA, N. T. V.; FALEIRO, F. G.; BRAGA, M. F.; PEIXOTO, J. R. Domesticação de espécies da flora nativa do Cerrado. In: PARRON, L. M.; AGUIAR, L. M. S.; DUBOC, E.; OLIVEIRA-FILHO, E. C.; CAMARGO, A. J. A.; AQUINO, F. G. (Ed.). Cerrado: desafios e oportunidades para $O$ desenvolvimento sustentável. Planaltina: Embrapa Cerrados, 2008.

KLINK, C. A.; MACHADO, R. B. A. Conservação do Cerrado brasileiro. Megadiversidade, v.1, n.1, p. 147-155, 2005.

RIBEIRO, J. F. BRITO, M. A.; SCALOPPI JUNIOR, E. J.; FONSECA, C. E. L. Araticum (Annona crassiflora Mart.). Jaboticabal: Funep, 2000.

SAS. SAS/STAT 9.2 User's Guide 2. ed. Cary: SAS Institute, 2009.

RIZZINI, C. T. Dormancy in seeds of Annona crassiflor Mart. Journal of Experimental Botany. v. 24, n. 78, p.117-123, 1973. https://doi.org/10.1093/jxb/24.1.117

SILVA, E.A.A.; MELO, D.L.B.; DAVIDE, A.C.; BODE, N.; ABREU, G.B.; FARIA, J.M.R.; HILHORST, H.W.M. Germination ecophysiology of Annona crassiflora seeds. Annals of Botany, v. 99, n. 5, p. 823-830, 2007. https://dx.doi.org/10.1093\%2Faob\%2Fmcm016

TAIZ, L.; ZEIGER, E. Fisiologia vegetal. Porto Alegre: Artmed, 2013.

TELLES, M.P.C.; VALVA, F. D.; BANDEIRA, L. F.; COELHO, A.S.G. Caracterização genética de populações naturais de araticunzeiro (Annona crassiflora Mart. - Annonaceae) no Estado de Goiás. Revista Brasileira de Botânica, v. 26, n. 1, p. 123-129, 2003. http://dx.doi.org/10.1590/S0100$\underline{84042003000100013}$

ZIMMERMANN, F. J. P. Estatística aplicada à pesquisa agrícola. Brasília: Embrapa, 2014. p. 1946.
Recebido para publicação em 08/10/2017

Revisado em 27/03/2018

Aceito em 02/04/2018 